ISBN 978-81-933894-6-1

7th International Conference on Recent Trends in Science, Engineering and Technology

(RTSET - 2017)

London (U K) June 29-30, 2017

\title{
Enhancement of Quasi-Static Puncture Resistance Behaviors of Trixie Fabric/Polyester Hybrid Composites
}

\author{
Magdi Elmessiry, Affaf Aloufy, Samar Abd-Ellatif and Marwa Elmor \\ Textile Department, Faculty of Engineering, Alexandria University, Egypt
}

\begin{abstract}
Various composite products are made of polyester polymers reinforced with synthetic fibers. In this research work, series of Triaxial fabrics are prepared using Polyester, Kevlar 29 and Vetran. The effect of material type on quasi-static puncture resistance is studied comparatively. The failure mode of the fabrics is analyzed. Findings indicate that the material type affects the quasi-static puncture resistance property of Triaxial fabrics. The contact pressure of fabric-probe represents the main resistance during the quasi-static puncture processes leading to the breakage of the fibers under penetration of the probe caused by tensile stress. The puncture resistance of the triaxial fabric/polyester composite was enhanced through the adding of a certain percentage of glass nanoparticles to the polyester polymer. The polyester/glass Nanoparticle matrix show better puncture resistance than ordinary polyester polymer matrix. The analysis of the results of the punching stress and the punching energy of the triaxial fabric/polyester/glass Nanoparticles composite is enhanced due to the application of the hybrid polyester/glass Nanoparticles using $2.8 \%$ glass particle volume fraction.
\end{abstract}

Keywords: puncture resistance, Triaxial fabrics, glass nanoparticles, composites

\section{Introduction}

Conventional laminates, fabric reinforced polymer materials have contemporary a number of advantages: such as some better overall punching through the thickness strength properties including superior impact damage resistance and improved fatigue performance [1,2]. Fiber-reinforced polymer-matrix composites are intended as the most encouraging material in advanced composites and especially hybrid composites [3, 4]. In a hybrid composite, two or more reinforcements are utilized into a single matrix to gain the composite properties diversity [5].The hybrid composite with an opposite combination of reinforcements and filler is urged to gain superior strength performance in numerous innovative applications. Wherein, nanoparticles are being utilized as an alternative tool for enhancing mechanical and thermal properties of fiber-reinforced polymer composites [6, 7]. Polyester is one of the fibers most commonly used in the composites industry. It's most often used in sheet molding compound, bulk molding compound and with glass fiber in industrial, construction, infrastructure fields as well as in other applications [8,9]. The use of nanoscale fillers is leading to the development of polymer nanocomposites and represents a radical alternative to these conventional polymer composites [10, 11]. There are several types of fillers such as quartz, amorphous silica, glass fillers with metals, colloidal silica, ceramics, organically modified ceramics/ORMOCERS, carbon nanotube, silver nanoparticles, gold nanoparticles, alloy nanoparticles, magnetic nanoparticles, nanoclay particles [12-13]. Several weave structures fabrics have been used as reinforcement; nevertheless, Triaxial fabrics are scarcely investigated. Triaxial weave has basically three sets of yarns as \pm bias ( \pm warp) and filling [14-16]. They interlaced to each other at about $60^{\circ}$ angle to form the fabric. Increasing inter-yarn friction has the potential to improve fabric ballistic performance without adding to its weight [17]. Triaxial structures can provide superior performance in applications wherein fabrics are loaded in all or several directions, rather than uniaxial. This paper studies the effects of the addition of glass nanoparticles utilized as filler in order to enhance the mechanical properties of polyester resin applied for manufacturing punch resisting, triaxial fabric/polyester hybrid composites. 


\section{Materials and Methods}

\subsection{Materials}

\subsubsection{Triaxial Fabric}

In this work, a number of Triaxial samples were made from different types of fibers Polyester, Vectran, Kevelar ${ }^{\circledR} 29$ with fabric weight $166,199,196.7 \mathrm{~g} / \mathrm{m} 2$ respectively. Triaxial pattern is basic with a count of (3.6 yarns $/ \mathrm{cm}$ ) in all three axes.

\subsubsection{The Glass Particles Preparation}

Mechanical processes, grinders were used to get glass nanoparticles. Materials are run through the mechanical treatment several times. After each pass, the particles are generally smaller and more uniform in diameter. The process is repeated till we get nanoscale glass particles. The average diameter of the glass particles reached $45 \mathrm{~nm}$ with CV 20\%. Figure 1. shows the morphology of glass particles.

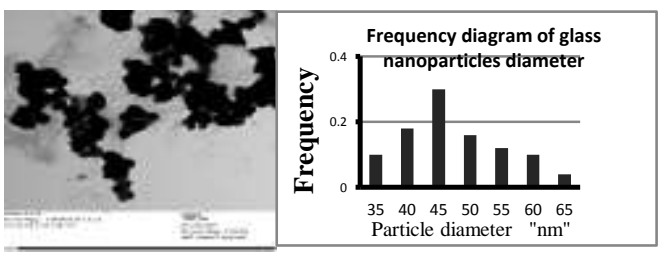

Figure 1. TEM of the glass particles

\subsection{Composite Manufacturing}

Composite panels were fabricated by resin transfer molding using two-dimensional Triaxial preforms with a $\left[0 \%+60 \%-60^{\circ}\right]$ architectures. Polyester resins of the following specifications were used as matrix: Tensile Strength 55 (MPa) Modulus of Elasticity 4 (GPa), Density $1.1(\mathrm{~g} / \mathrm{cm} 3)$ Flexural Strength 205 (MPa). Two sets of polyester resins with nanoparticles 5, 9, 13 and $15 \mathrm{wt}$. \% polyester resin were prepared. Casting composite was done by applying polyester resin/ nanoparticles using Triaxial fabric as reinforcement to form a single laminate or double laminate composite. Several reinforcement materials were used: polyester, Vectran and Kevlar 29.

\subsection{The Punching Test}

The punching test was carried out on a Universal Strength Tester device, Figure 2- a., with load capacity 500 $\mathrm{N}$ provided with punching attachment shown in Figure 2-b. The punching probe dimension is given in Figure 2c. the cross-head displacement rate $10 \mathrm{~mm} / \mathrm{min}$. The results reported represent averages of five samples. Puncture resistance is defined by the force exerted by a steel stylus of defined dimensions to puncture a test specimen held on a sample holder. The punching stress can be expressed as;

$$
\sigma=\frac{\text { maxim pentration force }}{t * \pi D_{\text {blade tip }}}
$$

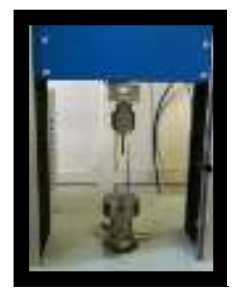

(a) Universal strength tester

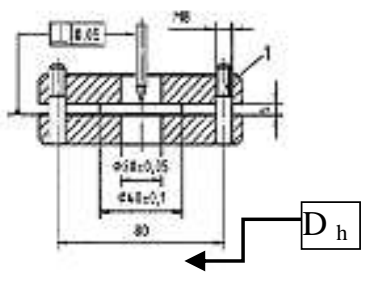

(b) sample holder

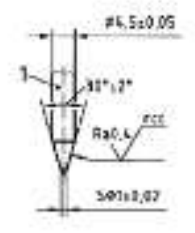

Dimensions in mm

Fig 2- a, b, c. Punching Testing device 
Where; $\mathrm{t}$ - The thickness of the matrix, $\mathrm{D}_{\text {blade tip }}$ - Diameter of tip of the blade

\section{Results and Discussion}

\subsection{Punching Stress of the Triaxial fabric}

The Triaxial fabric has interlacements; generally, the fabric has large open areas between the interlacements. Depending on the number of yarns/cm in each direction openings of hexagonal shapes are formed as illustrated in Figure 3.The mechanism of the punching of the Triaxial fabric is quite different from the punching of knitted or woven fabric depending on: The size of the blade tip diameter $\mathrm{D}_{\text {blade tip, }}$ the size of hexagonal opening between the yarns and yarn properties. If the radius of the blade tip is less than the apothem of the regular hexagonal, $\mathrm{h}$ Side length, then the tip can pass freely through the fabric, as well as the upper part of the blade if the area of the top part of the blade to pass freely through the fabric,

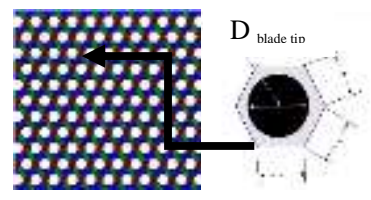

Figure 3 . Triaxial fabric

$$
\mathrm{A}<=1.5 h^{2} \sqrt{3}
$$

Consequently, the diameter of the blade should be $<\sqrt{\frac{4 A}{\pi}}$

In order to assure that the blade will punch the traiaxial fabric, the diameter blade tip should be;

$$
\geq \frac{h}{2} \sqrt{3}+2 d
$$

Where; $d$ - The width or diameter of the yarns, and $\mathrm{h}$ - The spaces between the yarns

The maximum punching force, in this case, will be the force creating strain equal to yarns failure strain Ey at the yarns intersection at punching points a, b, c, d, e, f; Figure 4. This will give the maximum value of punching force. The forces applied to the yarn, Figure 5, under the pressing of the blade will be: Pressure force P.The value of the friction force between the yarns depends on the magnitude of the forces on sets of the yarns which can be considered enough to prevent the sliding of the yarns against each other. Consequently, the value of punching force leads to strain of the yarns, given ey - yarn breaking strain, Ey - Young's modulus of the yarn.

$$
P=2.355(d)^{2} \text { \&y Ey } \cos \theta
$$

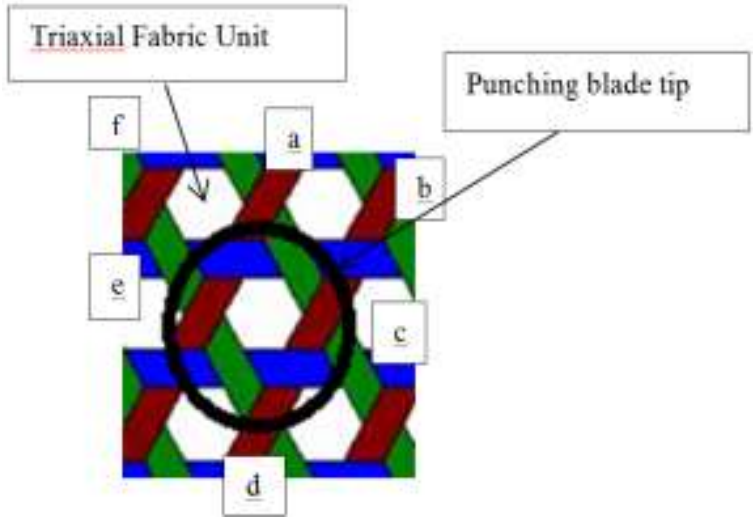

Fig 4. Punching of Triaxial fabric unit
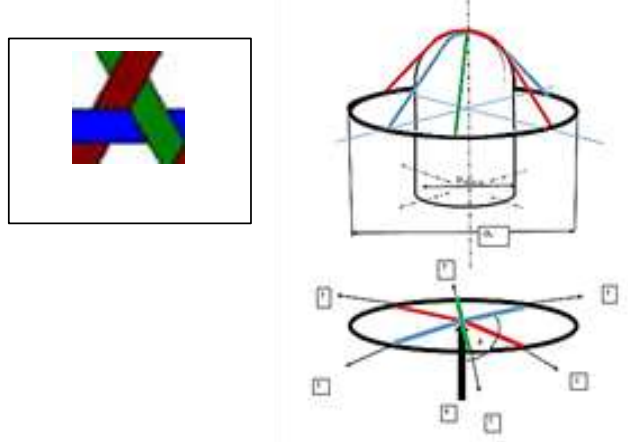

Fig 5. Force acting on the intersection of yarns 
The further displacement of the blade tip will cause more strain in the yarn till its failure. If the unit cell number of yarn intersections in the punched area is $\mathrm{n}$; then the total value of the maximum punching stress is the sum of the failed ones. In other cases when the blade tip diameter is $<0.5 \mathrm{~h} \sqrt{3}$, the value of punching force will be minimum hence the tip will pass through the opening between the yarns and only friction between the blade body and yarns are recorded. Between these two extremes punching force will vary depending upon the penetration location when the blade tip penetrates through the Triaxial fabric and the number of yarn intersections in the punched area.

\subsection{The Punching Force of Triaxial Fabrics}

Figure 6 gives the punching force -Blade displacement curves for different types of filament.

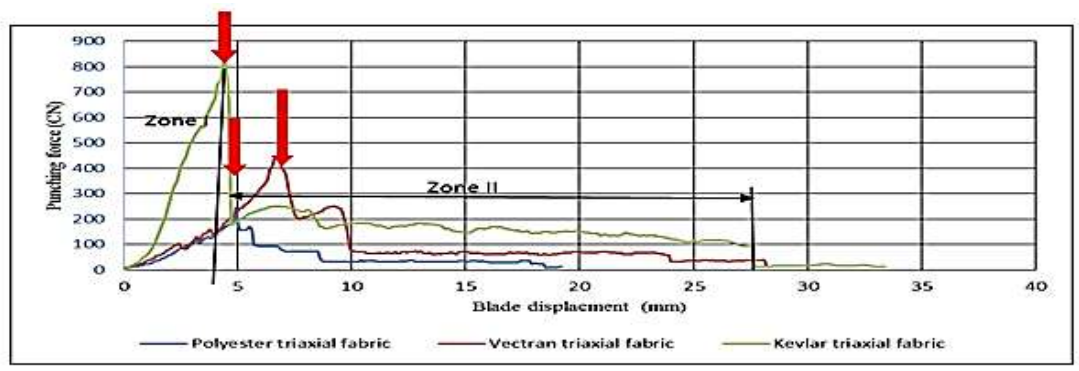

Figure 6. The Punching Behaviour for the different Triaxial Fabrics

As indicated in Figure 6 polyester filaments which have less coefficient of friction than other materials show low resistance force to the penetration of the blade in zone II. The results of punching stress for the different samples of Triaxial fabric are given in Table 1. as discussed above, punching forces for the Triaxial fabrics suffer from the high value of $\mathrm{CV} \%$. The values of punching forces depend on the first positioning of the blade tip relative to the yarns intersection.

Table 1. Triaxial samples punching properties

\begin{tabular}{|l|l|l|l|l|}
\hline \multirow{2}{*}{ Sample code } & \multicolumn{2}{|l|}{ Punching stresses } & Blade displacement mm & Punching energy \\
\cline { 2 - 5 } & $(\mathrm{CN})$ & CV\% & $(\mathrm{mm})$ & $\mathrm{mJ}$ \\
\hline P & 245.3 & 62.496 & 4.9 & 3.96 \\
\hline V & 461 & 30.86 & 6.8 & 11 \\
\hline K & 836.7 & 87.087 & 4.4 & 15.04 \\
\hline
\end{tabular}

\subsection{Punching Stress Triaxial Fabric/Polyester/ Glass Nanoparticles Composite}

Triaxial fabric /polyester/ glass nanoparticles composite single and double laminate using glass nanoparticles with volume fraction $\mathrm{Vg} 2.8 \%$ were manufactured using different types of fibers the fiber volume fraction is approximately $10 \%$. The mechanism of failure of the Triaxial fabric/polyester/glass nanoparticles composite is completely different from that of polyester/ glass nanoparticles composite. As illustrated in Figure 7, the punching of the composite leads to the distribution of the strain on the larger area around the blade tip penetration point and more yarns will participate in the punching resistance increasing composite fracture toughness. The value of the maximum punching stress the composite can withstand without final fracture depends on both composite material and thickness [18]. Figure 7 illustrates the failure of single laminated hybrid Triaxial fabric/polyester/glass nanoparticles composite with Vg 2.8\% glass nanoparticles and composite thickness $2 \mathrm{~mm}$. The total failure area $\left(\pi \mathrm{D}_{\mathrm{b}}{ }^{2} / 4\right)$, and the number of interlacement properly deformed under the punching load increased. 


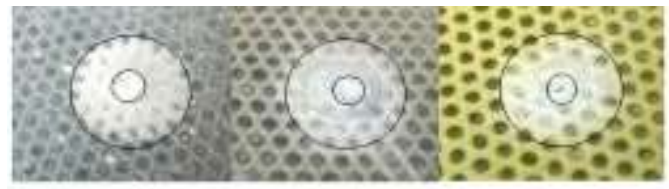

(a)

(b)

(c)

Fig 7. The failure of hybrid of Triaxial fabrics on face: (a) Polyester (b) Vectran (c) Kevlar.

The good binding of yarns of the Triaxial fabric to a matrix enables for stress transfer into the fibers through the fiber/matrix interface and allows the composite to deform under the punching force. The composite fracture toughness depends on the thickness of the composite which is a function of its stiffness [30]. As the thickness increases the fracture toughness is reduced.

The punching stress of the different multi-laminated composites, it confirms the failure of more yarns under the punching force at low values of glass fiber volume fraction.
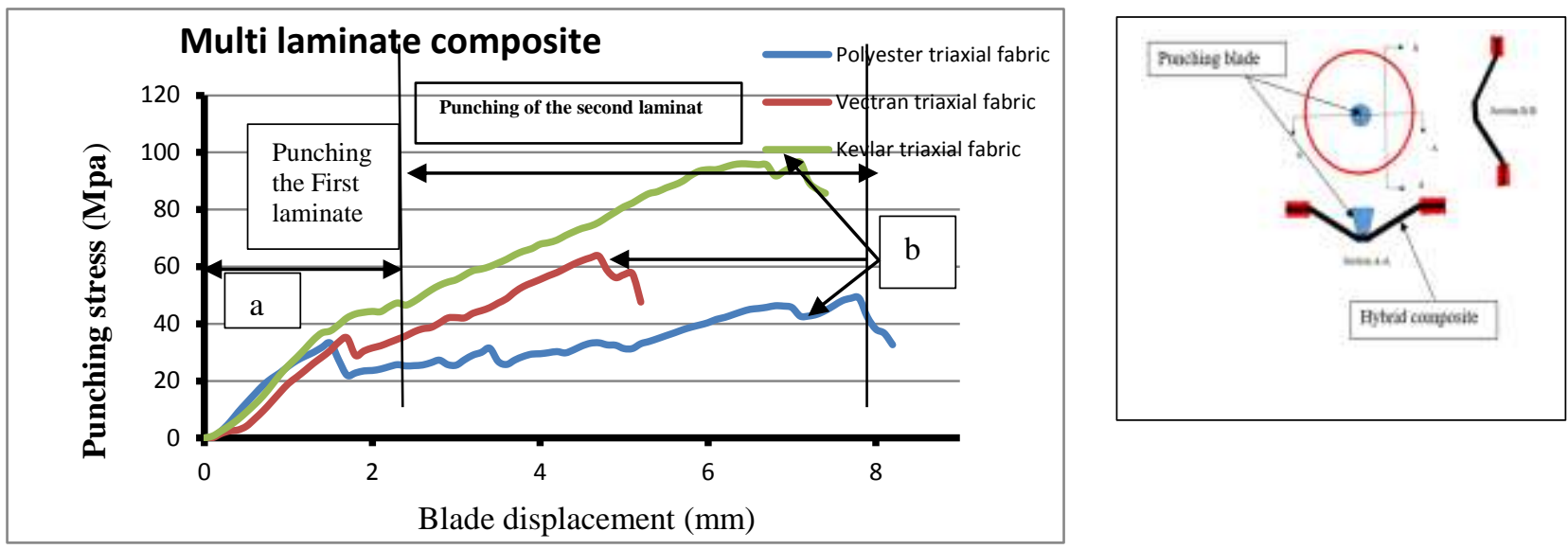

Fig:8. The punching behaviour of Multi-layers hybrid system of Triaxial fabrics

The punching stress for different composite structure single laminate and two laminates made of different types of fibers is given in Figure 8. When the probe tip penetrates the multi-laminated, composite the punching occurs in two stages: first: penetration through the first laminated and the punching force increases continuously till point "a". At the failure of the first laminate the probe tip pushes the second laminate which will deform as the punching force increases reaching its maximum value at the point " $b$ " and the punching stress falls as the blade moves through the composite. In this case, the results indicate that a number of laminated doesn't significantly affect the punching stress, Figure 9. This may be due to good binding of the yarns of the Triaxial fabric to a matrix in the presence of openings between the yarns of the triaxial fabric, Figure 9. Moreover, the composite has fewer tendencies for the delamination under punching stress. The kevelar29 gives the best punching resistance of the single laminated as illustrated in Figure 9.

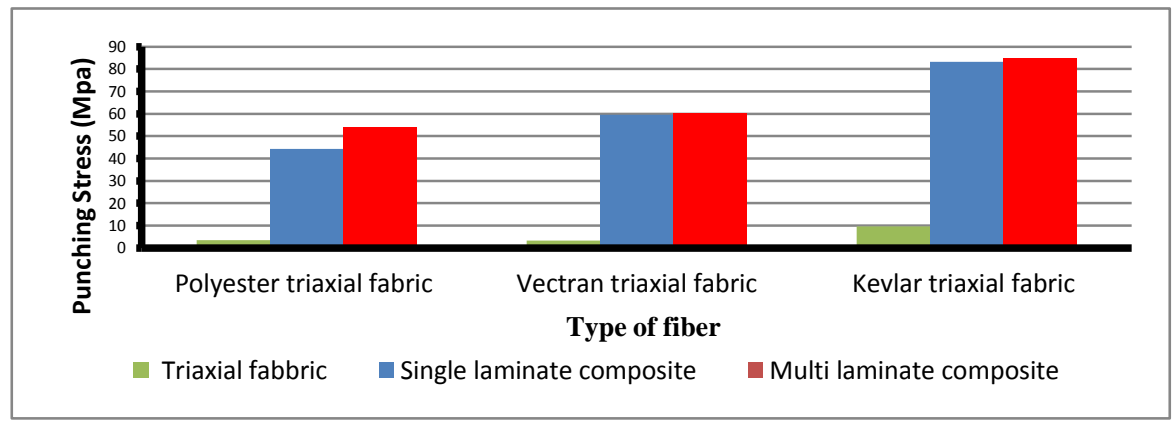

Fig: 9. Punching stress of Triaxial fabrics with different hybrid structures. 


\subsection{Punching Energy of Triaxial fabric/polyester/glass nanoparticles}

The punching energy is the energy to penetrate the blade through the sample described as;

$$
E p=\int_{0}^{x p} P(x) d x
$$

Where ; $\quad \mathrm{P}(\mathrm{x})$ - Punching force function of blade displacement, $\mathrm{x}$ - Blade displacement

Figure 10. shows the punching energy for different reinforcement fibers, kevelar shows the better results. As expected, the single laminated composites have better results than multi-laminated composites due to the effect of delamination of the composite performance during the penetration of the blade tip. The kevelar29 gives the best punching energy.

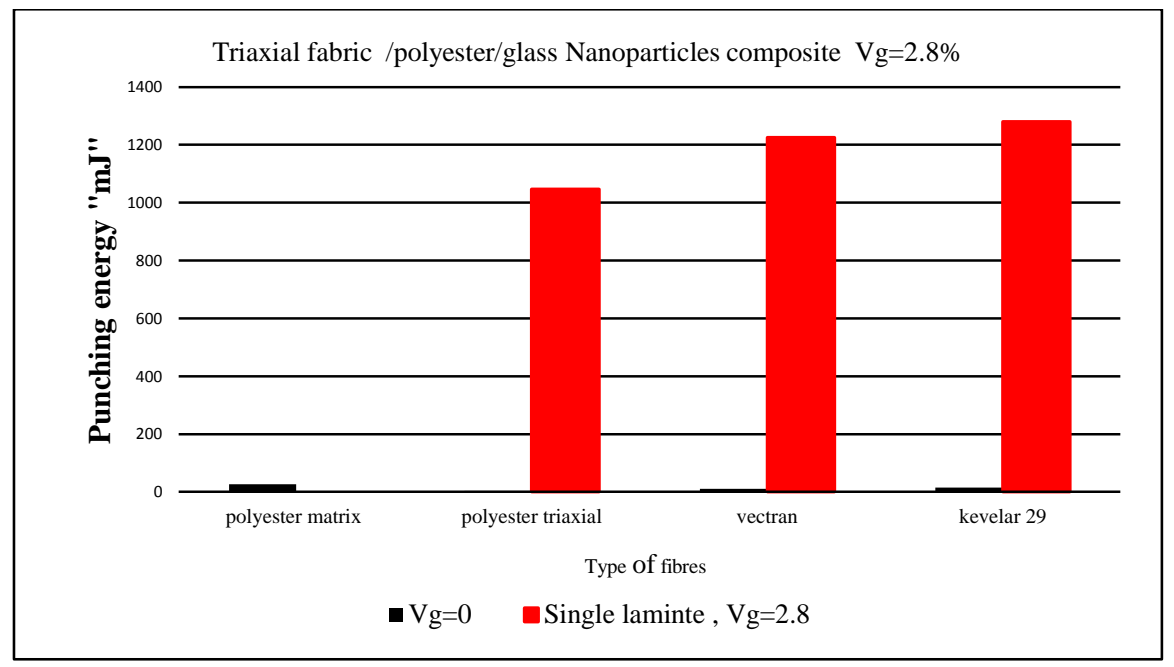

Fig:10. Punching energy of Triaxial fabrics single and double laminated composite

\section{Conclusion}

Punching-resistant performance of Triaxial fabric composites is strongly affected by fabric specifications, the percentage of glass nanoparticles, and the type of fibers. Results show that the punching resistance performance of composites can be significantly improved by adding a small percentage of glass nanoparticles to the polyester matrix. The punching resistance of the Triaxial fabric/polyester/glass nanoparticle hybrid composites shows a tremendous increase compared to Triaxial fabric/polyester matrix. It was proved that Kevlar 29 fibers/polyester/glass Nanoparticle composite has the highest punching resistance

\section{References}

[1] T. Black, R. Kosher, "Non Metallic Materials: Plastic, Elastomers, Ceramics and Composites, In : Materials and Processing in Manufacturing", (162-194), John Wiley \& Sons, Inc, 2008,USA .

[2] P. Mouritz, K. Bannister, J. Falzon, H. Leong, "Review of Applications for Advanced Three Dimensional Fibre Textile Composites", Compos. Part A1999 30, 1445-1461.

[3] K. Saw, C. Datta, "Thermomechanical properties of jute bagasse hybrid fiber reinforced epoxy thermoset composites", BioResources 2009,4: 1455-1476.

[4] M. El Messiry," Natural fiber polymer composites engineering”, Apple Academic Press Inc, USA .

[5] M. Jawaid, A. Othman, N. Saba, et al., "Effect of chemical modifications of fibers on tensile properties of epoxy hybrid composites", Int. J. Polym. Anal. Charact. 2014; 19:391-403.

https://doi.org/10.1080/1023666X.2014.904081

[6] A. Yasmin, I. Daniel, "Mechanical and thermal properties of graphite platelet/epoxy composites", Polymer. 2004;45:8211-8219. 
https://doi.org/10.1016/j.polymer.2004.09.054

[7] B. Debelak, K. Lafdi, "Use of exfoliated graphite filler to enhance polymer physical properties." Carbon. 2007;45:1727-1734. https://doi.org/10.1016/j.carbon.2007.05.010

[8] [8] B. Fiedler, F. Gojny, M Wichmann, et al., "Fundamental aspects of nano-reinforced composites", Compos. Sci. Technol. 2006;66:3115-3125

[9] Composites world, http://www.compositesworld.com/zones/polyesters-for-composites.

[10] K. Gaikwad, S. Ko "Overview on in Polymer-Nano Clay Composite Paper Coating for Packaging Application", J Material Sci Eng 2015, 4:151. doi: 10.4172/2169-0022.1000151. https://doi.org/10.4172/2169-0022.1000151

[11] A. Balazs, T. Emrick, T. Russell, "Nanoparticle Polymer Composites: Where Two Small Worlds Meet", Science 17 Nov 2006: Vol. 314, Issue 5802, 1107-1110. https://doi.org/10.1126/science.1130557

[12] S. Hasan, “A Review on Nanoparticles: Their Synthesis and Types.", Res. J. Recent. Sci 2015, Vol. 4(ISC-2014), 9-11.

[13] K. Gaikwad, S. Ko, "Overview on in Polymer-Nano Clay Composite Paper Coating for Packaging Application", J Material Sci Eng 4: 151.

[14]G. Chaiab, S. Zhu, "A review of low-velocity impact on sandwich structures, Proceedings of the Institution of Mechanical Engineers”, Part L: JM DA. 2011, 207-225.

[15] N. Hassim, M. Ahmad, W. Yunus. W. Ahmad, A. Harris, M. Yahya, "Cutting resistance of natural rubber latex unidirectional coated fabrics", Journal of Industrial Textiles, originally published online 28 November 2011. http://jit.sagepub.com/content/42/2/118

[16] J. Moreland, "Production and Characterization of Aramid Copolymer Fibers for Use in Cut Protection", PhD thesis, Clemson University, December 2010.

[17] M. El Messiry, E. Eltahan, "Stab resistance of triaxial woven fabrics for soft body armor". Journal of Industrial Textiles2016, Vol. 45(5) 1062-1082. https://doi.org/10.1177/1528083714551441

[18] M. Maleque , M. Salit, "Mechanical Failure of Materials". Chapter Materials Selection and Design, Part of the series Springer Briefs in Materials, 17-38. 